\title{
Unilateral Tubarial Oncocytic Papillary Cystadenoma Presenting with Epistaxis
}

\section{Epistaksis ile Prezente olan Tek Taraflı Tubarial Onkositik Papiller Kistadenom}

\author{
(D) Nurul Syuhadah HASNY1,2, (D) Fatihatul Munirah AMIRUDDIN33, (D) Faezahtul Arbaeyah HUSSAIN3, \\ (D) Baharudin ABDULLAH1,4
}

'Universiti Sains Malaysia Health Campus School of Medical Sciences, Department of Otorhinolaryngology - Head and Neck Surgery, Kota Bharu, Malaysia

${ }^{2}$ Hospital Raja Perempuan Zainab II, Clinic of Otorhinolaryngology - Head and Neck Surgery, Kota Bharu, Kelantan, Malaysia

32Department of Pathology, School of Medical Sciences, Universiti Sains Malaysia Health Campus, Kelantan, Malaysia

${ }^{4}$ Hospital Universiti Sains Malaysia, Health Campus, Kota Bharu, Kelantan, Malaysia

\begin{abstract}
Oncocytic papillary cystadenoma (OPC) is a relatively rare benign tumor of the salivary glands, frequently seen in minor salivary glands, and occasionally in major salivary glands, such as the parotid gland. Patients only become symptomatic upon progression of the swelling, causing obstructive symptoms depending on its location. To our knowledge, there are no reports of presentation with bleeding tumor. Herein, we report a case of an OPC of the right torus tubarius in a 54-year-old man who presented with recurrent epistaxis. Keywords: Oncocytic, benign, minor salivary gland, epistaxis
\end{abstract}

\section{öz}

Onkositik papiller kistadenom (OPC), tükürük bezlerinin nispeten nadir görülen iyi huylu bir tümörüdür, sıklıkla minör tükürük bezlerinde ve bazen de parotis bezi gibi majör tükürük bezlerinde görülür. Hastalar ancak şişliğin ilerlemesiyle semptomatik hale gelir ve şişliğin konumuna bağlı olarak obstrüktif semptomlara neden olur. Bildiğimiz kadarıyla kanamalı tümör ile başvuru bildirilmemiş̧ir. Biz burada, tekrarlayan epistaksis ile başvuran 54 yaşındaki erkek hastadaki sağ torus tubariusun OPC'sini sunduk.

Anahtar kelimeler: Onkositik, iyi huylu, minör tükürük bezi, epistaksis
Received: 10 October 2021 Accepted: 17 November 2021 Online First: 14 December 2021

Corresponding Author

Baharudin ABDULLAH

Universiti Sains Malaysia Health Campus School of Medical Sciences, Department of Otorhinolaryngology Head and Neck Surgery and Hospital

Universiti Sains Malaysia, Health Campus, Kota Bharu, Kelantan, Malaysia baharudin@usm.my ORCID: 0000-0001-9138-9215

\section{INTRODUCTION}

Epistaxis, or more specifically posterior epistaxis, is a common cause of otolaryngologic admission, especially in middle-aged to older adults, as they are more associated with systemic comorbidities and are more likely to be taking blood-thinning medications, such as antiplatelets and anticoagulants'. As posterior epistaxis is less likely to resolve spontaneously, it usually requires close observation or even posterior packing until the primary disorder is treated or resolved ${ }^{2}$. A sudden onset of recurrent epistaxis in adult men/older men without any history of using such drugs or a recent facial trauma is also the common presentation or warning sign for sinonasal diseases, particularly for malignant tumors, such as squamous cell carcinoma, minor salivary gland carcinoma, nasopharyngeal carcinoma, and lymphoma. Oncocytic papillary cystadenoma (OPC) is a very rare benign tumor commonly found in the salivary glands, mainly reported in minor salivary glands, and usually is observed in individuals aged 60-70 years ${ }^{3-6}$. A few cases 
reported were seen within the intraoral minor salivary glands and parotid glands, which all presented with a painless mass, whereas some cases were detected within the larynx, mainly at the supraglottic structures, and an increasing tumor size causes hoarseness, dysphonia, or rarely airway obstruction ${ }^{7}$. In 2020, Hwang et al. ${ }^{8}$ reported a case of oncocytic cysts of bilateral tori tubarii that presented with bilateral middle ear effusion (MEE). None of the cases reported had clinical presentation of bleeding tumor or epistaxis, like in our case.

\section{CASE REPORT}

A 54-year-old Malay man presented with a week history of unprovoked, recurrent epistaxis. Bleeding was more evident from the right side and resolves after 5-10 min of anterior nares compression. He had not experienced similar incidence, and there were no other pre-existing nasal symptoms, such as nasal congestion, rhinorrhea, anosmia, sneezing, itchiness, or any other aerodigestive symptoms. On further questioning, he is an active smoker but had no history of trauma, bleeding tendencies, and intake of blood-thinning medications or supplements. Upon further assessment, he was hemodynamically stable with no active bleeding. He had no evident nasal deformity, whereas nasoendoscopy showed blood clots along the middle meatus bilaterally with left septal spur, but no bleeding point or lesions within nasal cavity.

Posteriorly, we noted a small single hemorrhagic cystic-like lesion at the anterior surface of the right torus tubarius that was nonpulsatile and no active bleeding, whereas the fossa of Rosen Mueller was clear (Figure 1). Bilateral ear and neck examinations were unremarkable. Blood parameters had no coagulopathies, and he was discharged with well status. Contrast-enhanced computed tomography (CECT) of the paranasal sinus (PNS) was performed at the outpatient setting, and no sinonasal, nasopharyngeal, or right tubarial lesions were detected (Figure 2). Upon follow-up, the cystic lesion was persistent, but no active epistaxis was observed. In view of the findings, a biopsy was taken under endoscopic guidance using punch biopsy forceps in the clinic under local anesthesia. Only minimal bleeding occurred after biopsy, which resolved with ice compression and nasal packing using Moffet's solution. With the limited surgical field and fear of over excision of the normal tubarial tissue which may cause epistaxis or scarring later, only a small yet sufficient tissue was obtained without attempting to manipulate further. Symptoms resolved the following month with no additional ear complaints, and only a small residual lesion was seen on endoscopy (Figure 3). The final histopathology examination revealed the lesion as an OPC (Figure 4a,b). As the lesion was not causing any disturbances, he was not kept for further evaluation or surgical intervention.

\section{DISCUSSION}

Minor salivary glands are small, abundant, and distributed all along the aerodigestive tracts ${ }^{9}$. Nevertheless,

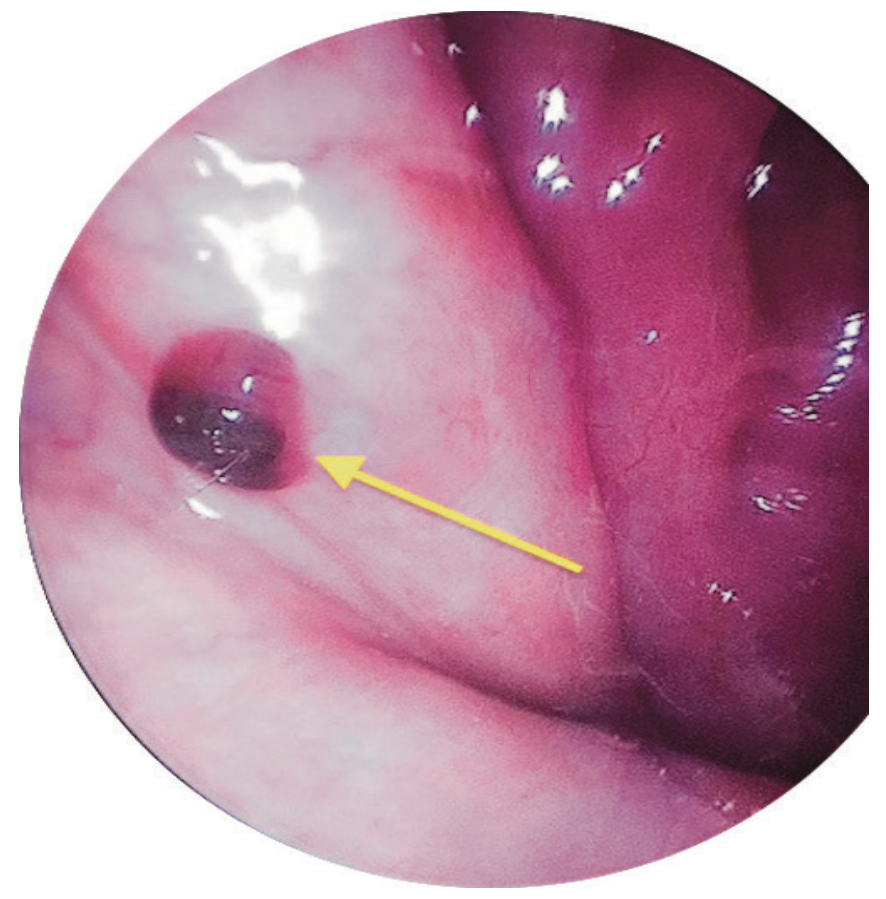

Figure 1. Hemorrhagic cystic-like lesion (arrow) found at the right torus tubarius.

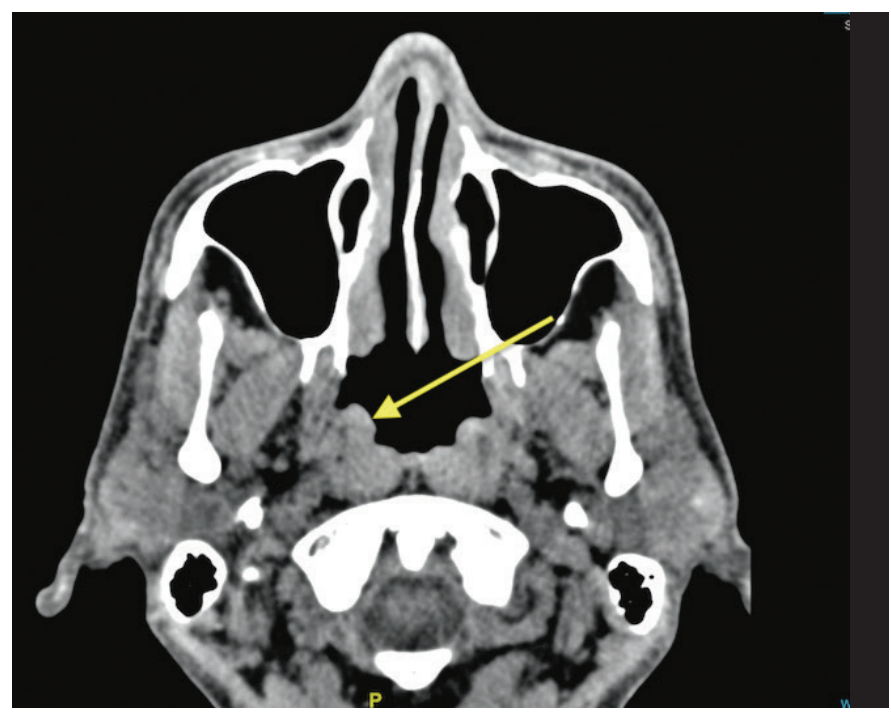

Figure 2. Contrast-enhanced computed tomography of the paranasal sinus in axial view shows no evident soft tissue lesion at the right torus tubarius (arrow). 
they are frequently seen and documented within the oral cavity such as the palate, tonsillar area, buccal mucosa, tongue, and lips ${ }^{9-11}$. Occasionally, it may be found in the PNSs, pharynx, and larynx and barely found within the nasal cavity or the nasopharynx ${ }^{9}$. However, in 2020, Valstar et al. ${ }^{12}$ discovered a pair of (major) tubarial salivary glands, detected by positron emission tomography/ computed tomography with prostate-specific membrane antigen ligands.

Minor salivary gland tumors (MSGTs) account for $<20 \%$ of all salivary gland tumors, and only $2-3 \%$ of all head and neck neoplasms ${ }^{6,9.11}$.They are usually found in individuals aged 50-60 years with a slight female predominance ${ }^{3.11}$. In contrast to major salivary gland tumors where malignancy is unlikely, those arising from minor salivary glands are likely malignant with either adenoid cystic carcinoma or mucoepidermoid carcinoma as the most common ${ }^{9.11}$. Conversely, pleomorphic adenoma, albeit rare, is the most common benign MSGT. Nonetheless, MSGTs are mostly located intraorally, presenting either as a progressive painful mass, ulcerative lesion, or even as a painless swelling incidentally noted during dental examinations or upon a compressive sequela ${ }^{4,9.11}$.

OPC is an uncommon benign salivary gland tumor arising from the minor salivary glands. It occurs in only $2 \%$ of MSGT cases worldwide ${ }^{3,5}$. The lesion resembles Warthin's tumor; however, it does not demonstrate

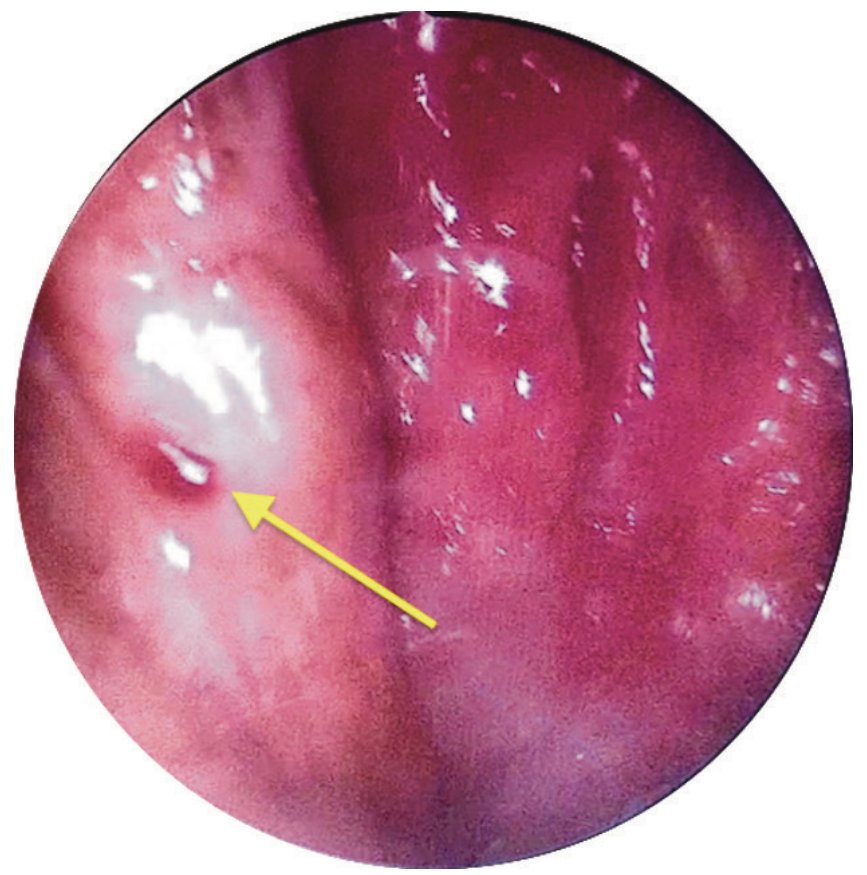

Figure 3. At 2 weeks post biopsy, a smaller lesion with no active bleeding was detected (arrow). lymphoid elements. Given their rarity, its cytological features are not well described ${ }^{4.5 .8}$. According to the World Health Organization histological classification of salivary gland tumors, OPC is a cystic lesion lined by oncocytic epithelium with occasional luminal papillary projections. They are mostly reported among those aged 70-80 years and strongly associated with smokers or tobacco users ${ }^{6,7}$. It mostly presents as a single cyst and rarely in a more diffuse pattern as multicysts ${ }^{6}$. In 2020, Hwang et al. ${ }^{8}$ reported a case of oncocytic cysts of bilateral tori tubarii. The patient presented with bilateral

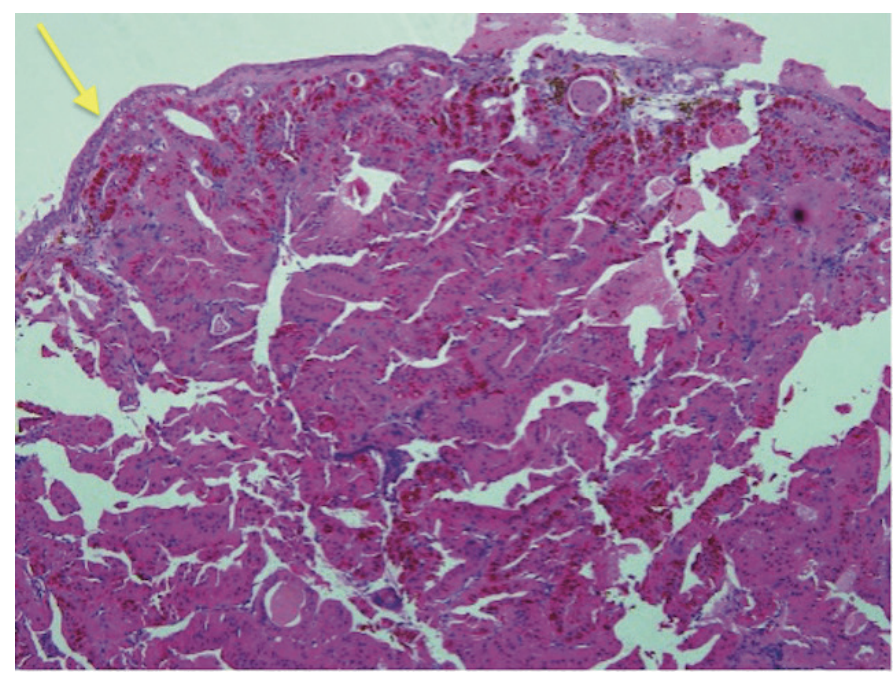

Figure 4a. A nodular lesion surrounded by respiratory-type epithelium (arrow), composed of oncocytic cells (hematoxylin and eosin staining, 100×).

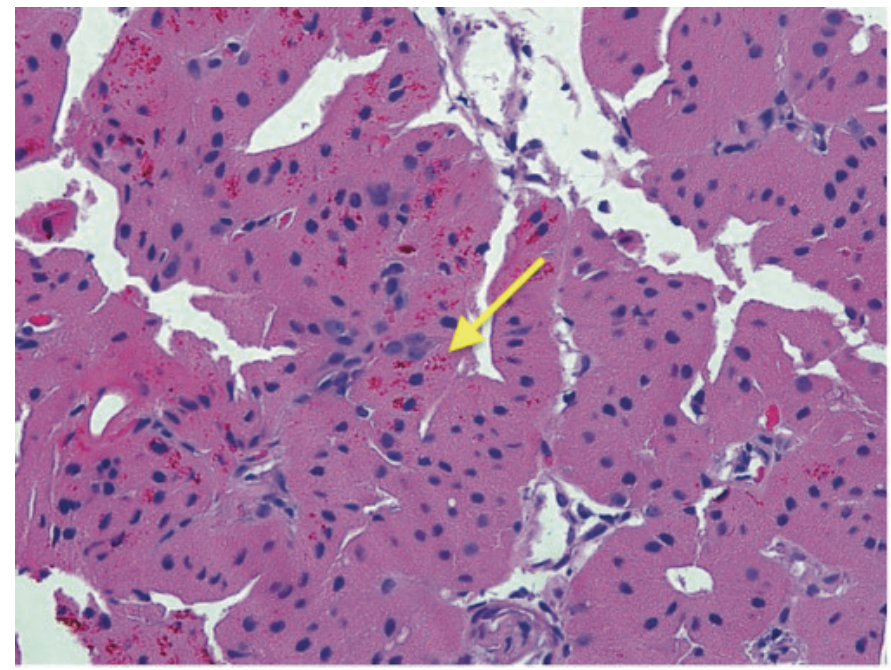

Figure 4b. Oncocytic cells forming glandular-like pattern with minimal intervening stroma. They emerge as larger cell with granular eosinophilic cytoplasm and small dark nuclei. Some of the cells contain hemosiderin material in the cytoplasm (arrow) (hematoxylin and eosin staining, 400×). 
MEE caused by hypertrophied, irregular lobular changes to the submucosal, leading to the initial eustachian tube (ET) dysfunction. The English literature from 1927 to 1960 had only recorded 16 OPC cases of 800 MSGT cases. None of these cases had arisen from the nasal cavity or nasopharyn $x^{3.5}$.

OPC, like its benign peers, are mostly asymptomatic, and occasionally detected as a painless slow-growing mass beneath the mucosa of the palate, lips, buccal mucosa, or even supraglottic structures. Swelling only becomes noticeable upon compression toward its surrounding structures ${ }^{5}$. CECT imaging to determine the characteristics of the lesion may not be beneficial in smaller lesions, whereas magnetic resonance imaging (MRI) is more valuable in larger or multiple masses ${ }^{8,9}$. Imaging data available are inadequate to prove the best diagnostic choice in view of the lack of reported cases and extremely rare recurrence after excision.

Determining the point of bleeding or the characteristics of the lesion with CECT is not necessarily helpful, as shown in our case, but it remains our first line of diagnostic imaging and is adequate to exclude vascular or more aggressive lesions that may be missed by the naked eye before performing a biopsy. Additionally, if the lesion was larger and the patient agreed for surgical excision, MRI can be performed to help delineate it apart from surrounding structures. In the presence of a vascularlooking mass or persistent epistaxis, CT angiography may be opted to map out the feeding vessels involved ${ }^{1.8}$.

Thus far, to our knowledge, no case was reported in the literature of an OPC arising as a unilateral, single lesion over the torus tubarius and presenting as recurrent epistaxis. Hence it is crucial to discuss beforehand with the reporting pathologist regarding the tissue diagnosis and clinical correlation. The final dilemma arises in whether to correlate the bleeding with the lesion itself. But as no other suggestive mass was discovered combined with the negative findings on CECT PNS, OPC remains the most probable cause of the epistaxis. Cessation of epistaxis after excision of the main bulk of the lesion further supports the diagnosis.

Most of the patients with OPC underwent single excision to relieve compressive symptoms, and all had extremely rare recurrence ${ }^{3-5}$. The patient, which was reported in 2020 with oncocytic cysts of the bilateral tori tubarii, did not undergo any excision in fear of scarring near the ET opening; therefore, treatment of the sequelae was addressed. MEE was resolved with a myringotomy and tube insertion of both ears, and continuous follow-up was implemented ${ }^{8}$.

OPC is an uncommon salivary gland tumor mostly arising from intraoral minor salivary glands and occasionally from the parotid gland or larynx. OPCs present as slow-growing painless tumors or their compressive sequelae. Cases of tubarial OPC may be under reported, and can only be identified upon presentation with otologic sequelae or nasal symptoms, such as epistaxis. The role of imaging is yet to be determined in the case of possible bleeding OPC and likely nonbeneficial in smaller lesions. As recurrence is rare, simple excision is the main treatment if the patient has no symptoms; otherwise, reassurance and observation are recommended.

Acknowledgements: A warm thanks to all involved in managing this case firsthand or indirectly.

\section{Ethics}

Informed Consent: Verbal consent for patient information was obtained directly from patient himself.

Peer-review: Externally peer-reviewed.

\section{Author Contributions}

Concept: N.S.H., Design: N.S.H., Data Collection and/or Processing: N.S.H., F.M.A., Analysis and/or Interpretation: N.S.H., F.M.A., F.A.H., B.A., Critical revision: F.A.H., B.A., Writing: N.S.H.

Conflict of Interest: The authors declare that they have no conflict of interest.

Financial Disclosure: The authors declared that this study has received no financial support.

\section{REFERENCES}

1. Rebella G, Basso L, Federici M, Castaldi A. Recurrent epistaxis of unknown origin: the role of imaging. Acta Neurol Taiwan. 2019;28:12630.

2. Chiu TW, McGarry GW. Prospective clinical study of bleeding sites in idiopathic adult posterior epistaxis. Otolaryngol Head Neck Surg. 2007;137:390-3.

3. Zhang S, Bao R, Abreo F. Papillary oncocytic cystadenoma of the parotid glands: A report of 2 cases with varied cytologic features. Acta Cytol. 2009;53:445-8.

4. Wilson DF, MacEntee MI. Papillary cystadenoma of ectopic minor salivary gland origin. Oral Surgery, Oral Med Oral Pathol. 1974;37:9158.

5. Goto M, Ohnishi Y, Shoju Y, Wato M, Kakudo K. Papillary oncocytic cystadenoma of a palatal minor salivary gland: A case report. Oncol Lett. 2016;11:1220-2.

6. Koh M, Nigam S. Oncocytic papillary cystadenoma of the larynx: a case report. Pathology. 2013;45:72. 
N.S. Hasny et al. Unilateral Tubarial Oncocytic Papillary Cystadenoma

7. EI-Naggar AK, Chan JKC, Grandis JR, Takata T. Slootweg PJ. WHO Classification of Head and Neck Tumours . 4th ed. Lyon: IARC; 2017. p. 347 .

8. Hwang JC, Dedhia RD, Bernard JE, Steele TO. Oncocytic Cysts of the Nasopharynx: A Case Report. Allergy Rhinol (Providence). 2020;11:2152656720956594. doi: 10.1177/2152656720956594.

9. Wyszyńska-Pawelec G, Gontarz M, Zapała J, Szuta M. Minor salivary gland tumours of upper aerodigestive tract: a clinicopathological study. Gastroenterol Res Pract. 2012;2012:780453. doi: 10.1155/2012/780453.
10. Sainudeen S, Sabujan A. Minor salivary glands and 'Tubarial Glands'Anatomy, physiology, and pathology relevant to radiology. J Radiol Clin Imaging. 2021;4:001-0014.

11. Jaber MA. Intraoral minor salivary gland tumors: a review of 75 cases in a Libyan population. Int J Oral Maxillofac Surg. 2006;35:150-4.

12. Valstar MH, de Bakker BS, Steenbakkers RJ, et al. The tubarial salivary glands: a potential new organ at risk for radiotherapy. Radiother Oncol. 2021;154:292-8. 